\title{
Hand-Gesture Recognition System For Dumb And Paraplegics
}

\author{
B.Yuva Srinivas Raja ${ }^{\# 1}$, G.Vimala Kumari ${ }^{* 2}$, K.Susmitha ${ }^{\# 3}$, CH.V.N.S Akhil ${ }^{\# 4}$, A. Sanhita ${ }^{\# 5}$ \\ \# Student of Electronics and Communication Department, Maharaj Vijayaram Gajapathi Raj College of \\ Engineering (A), Chintalavalasa, Vizianagaram, Andhra Pradesh-535005, India \\ ${ }^{1}$ yuvasrinivasraja@gmail.com , \\ 33alisettysusmitha@gmail.com, \\ 4akhil.chvns@gmail.com, \\ ${ }^{5}$ sanhita.arasada@gmail.com. \\ *Assistant Professor of Electronics and Communication Department, Maharaj Vijayaram Gajapathi Raj College \\ of Engineering (A), Chintalavalasa, Vizianagaram, Andhra Pradesh-535005, India \\ 2vimalakumari7@gmail.com
}

\begin{abstract}
In this paper, Hand-Gesture Recognition System helps the dumb people finding difficult in communicating with the society. These people give some gestures to communicate with the normal people but all the gestures given by the dumb cannot be understood. So,there is a necessary to have some media between the dumb and normal people. The system recognizes the gestures given by the dumb and display the message on the LCD according to the gesture. The glove with flex sensors is worn to the hand of the dumb and when the gesture is given it is sensed by the flex sensor then the system recognize the gesture. Paraplegics are the persons whose body parts below the belly will not work and find difficulty in using the appliances. The system also consists of accelerometer control the fan and light. The appliances can be controlled by tilting the accelerometer. An alert message with the help of a GSM can be sent to the concerned person of the paraplegic when the paraplegic is in trouble.
\end{abstract}

Keywords: ATMEGA128, Accelerometer, Flex Sensor , GSM Module

\section{INTRODUCTION}

PROBLEM: In the recent years, there has been a rapid increase in the number of dumb as well as paraplegics due to birth defects, accidents and oral diseases. When a speech impaired person speaks to a normal person, the normal person finds it difficult to understand and asks the dumb person to show gestures needs.

Dumb persons have own language to communicate, the only thing is that the language should be understood. The disabled as well as the people who cannot speak or have lost their ability to speak in some accident, it becomes a difficult task for them to convey their message within the society and along with that, these people find themselves difficult in using some of our home appliances too.

SOLUTION:Sign language is generally used by dumb and disabled people and it is a communication skill that uses gestures instead of sound to convey meaning simultaneously combining hand shapes, orientations and movement of the hands, arms or body and facial expressions to express fluidly a speaker's thoughts. But most of the time normal people find it difficult to understand this sign language and disabled persons finds it difficult to use home appliances. The problem can be overcome with the project called "HAND-GESTURE RECOGNITION SYSTEM FOR DUMB AND PARAPLEGICS”.

This project is implemented on Atmega128 board which uses accelerometer, flex sensors and a GSM module.

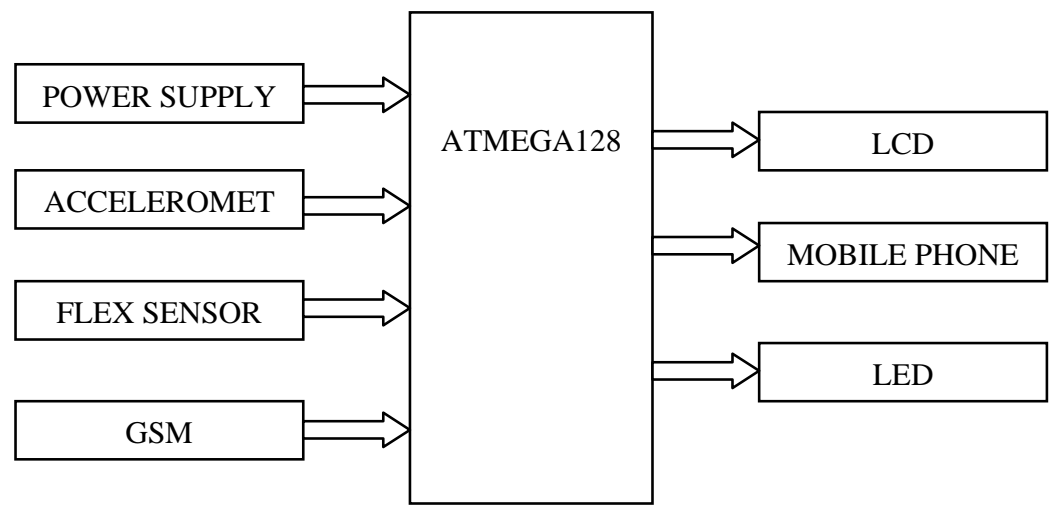

Fig 1 Block diagram of Hand gesture system 


\section{SENSORS}

A. FLEX SENSORS: Flex sensors, (from Latin word flectere, which means 'to bend') are also known well as bend sensors, which measures the amount of deflection caused by bending the sensor. There are many ways of sensing the deflection, from strain-gauge to hall-effect sensors.

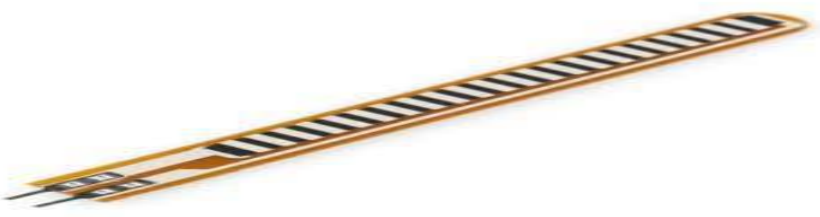

Fig 2 .Flex sensor

A property of bend sensors worth noting is that bending the sensor at one point to a prescribed angle is not the most effective use of the sensor. As well, bending of the sensor at one point to more than $90^{\circ}$ can permanently damage the sensor. Instead, bend the sensor around a radius of curvature. The smaller the radius of curvature and the more the whole length of the sensor is involved in the deflection, the greater the resistance will be (which will be much greater than the resistance achieved if the sensor is fixed at one end and bent sharply to a high degree).

B. ACCELEROMETER: An accelereometer is an electromechanical device, that measures the acceleration forces acting upon it. However, these forces may be static like the constant force of gravity pulling at your feet or some could be dynamic caused by moving or vibrating the accelerometer. Accelerometers are of two types some are analog and some are digital in design. The accelerometer that was used in this project is ADXL335.There will be three axes which are x,y,z axes.

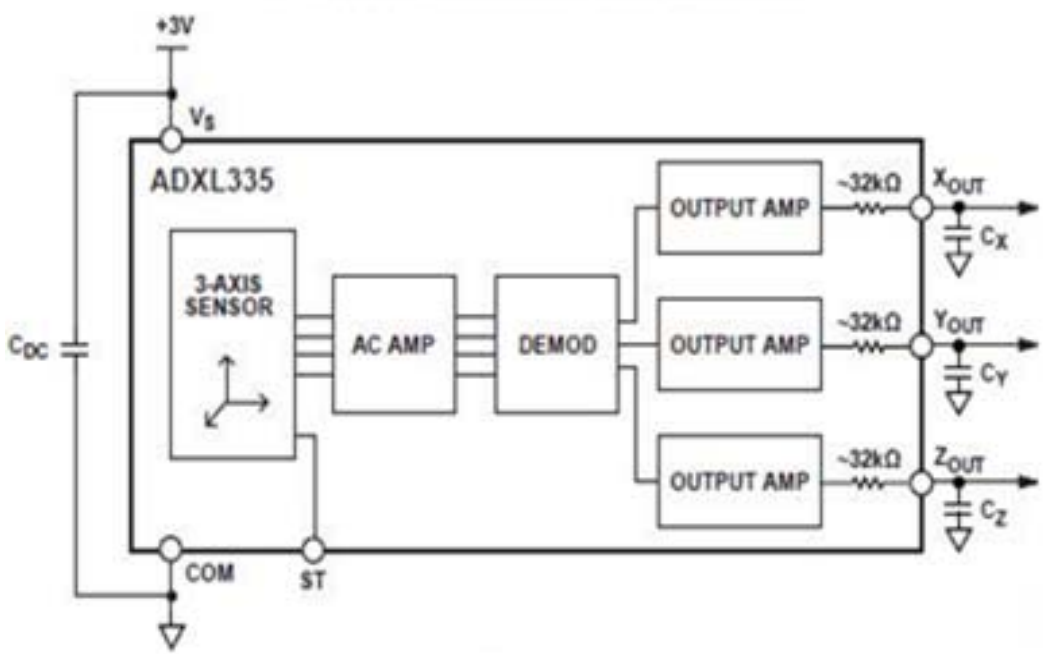

Fig 3 block diagram of ADXL335 Accelerometer

\section{III.WORKING}

This system is allowed to work on a single glove by simply wearing to the hand of a dumb or a paraplegic patient. Whereas the flex sensors are fixed along the fingers and the accelerometer on the hand. As we mentioned the properties of these sensors before itself, if this person shows different signs with folding the fingers in different ways there will be a change in the amount of deflection in flex sensor. In the same way, if the person tilt the hand in upward or downward direction there will be a change of acceleration forces. Due to these changes the respective analog values will occur. Every value is designed to have different signs and their respective messages through ATMEGE128 module and is displayed on LCD screen too. WinAVR is the programme used here to work in real time. An ADC is used to convert the analog values of sensors to digital values to work on ATMEGA128. Furthermore, a GSM can be interfaced if the concerned person is far away from the dumb ones. 


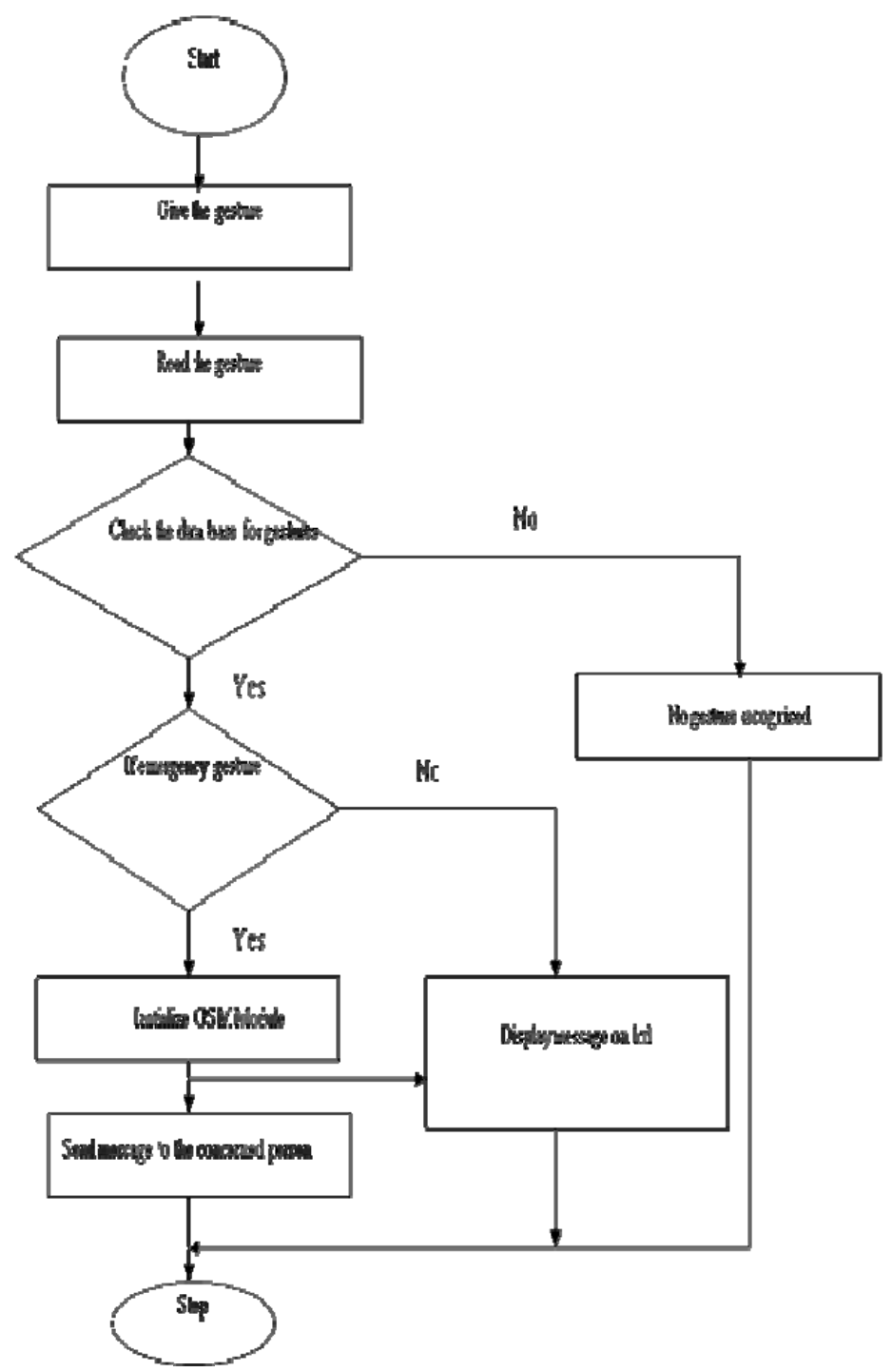

IV. RESULTS

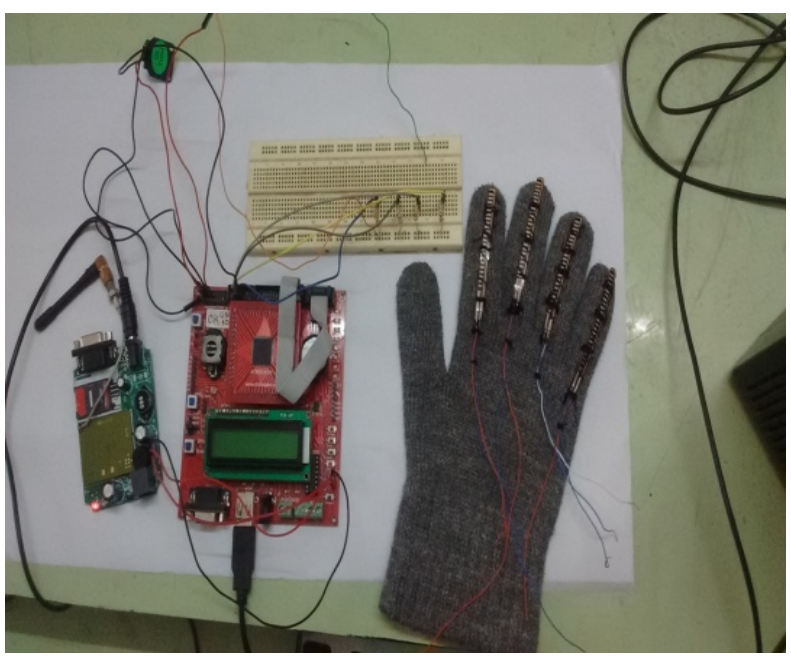

Fig 4 Result showing the set-up 
ISSN (Print) : 2319-8613

ISSN (Online) : 0975-4024

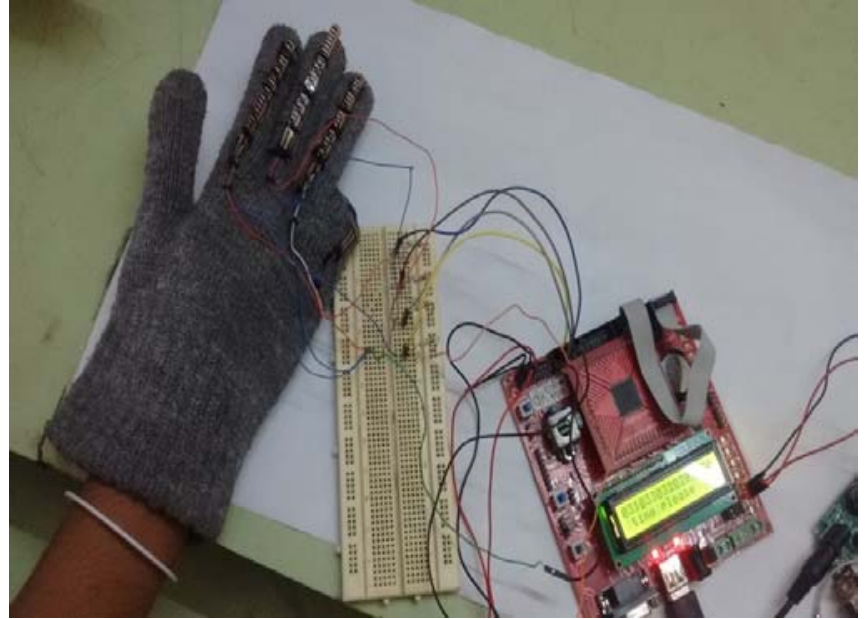

Fig 5 Showing message (TIME PLEASE)

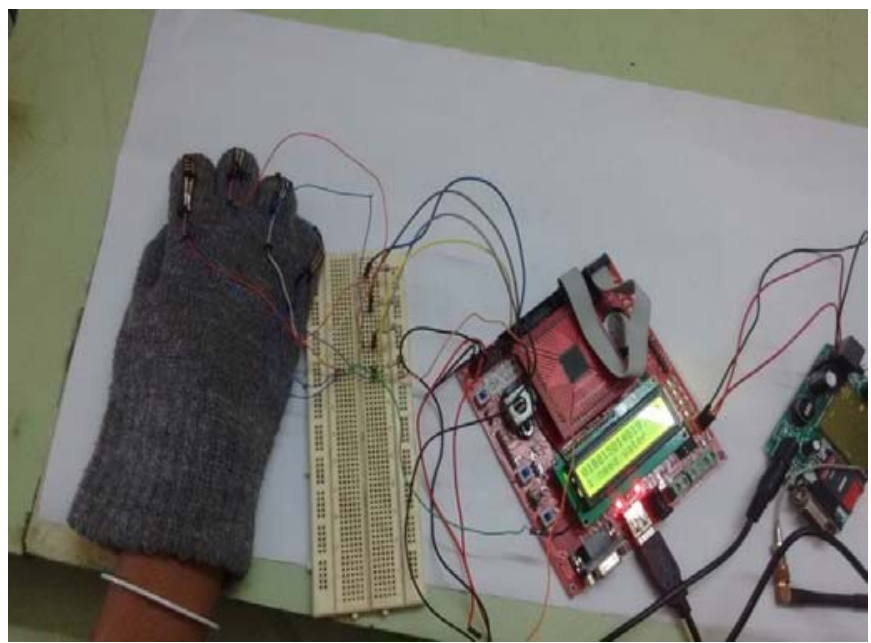

Fig 6 showing message (I NEED WATER)

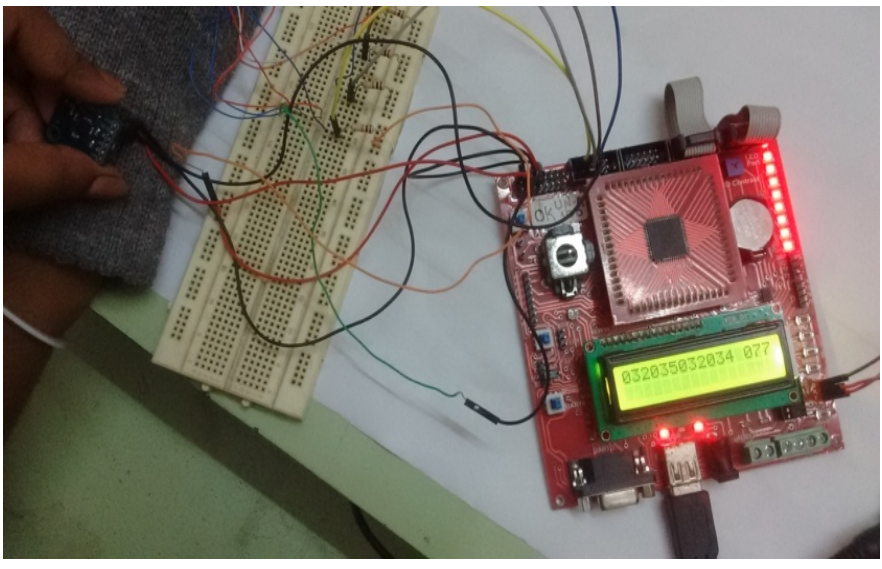

Fig 7 showing message with accelerometer (ON condition) 


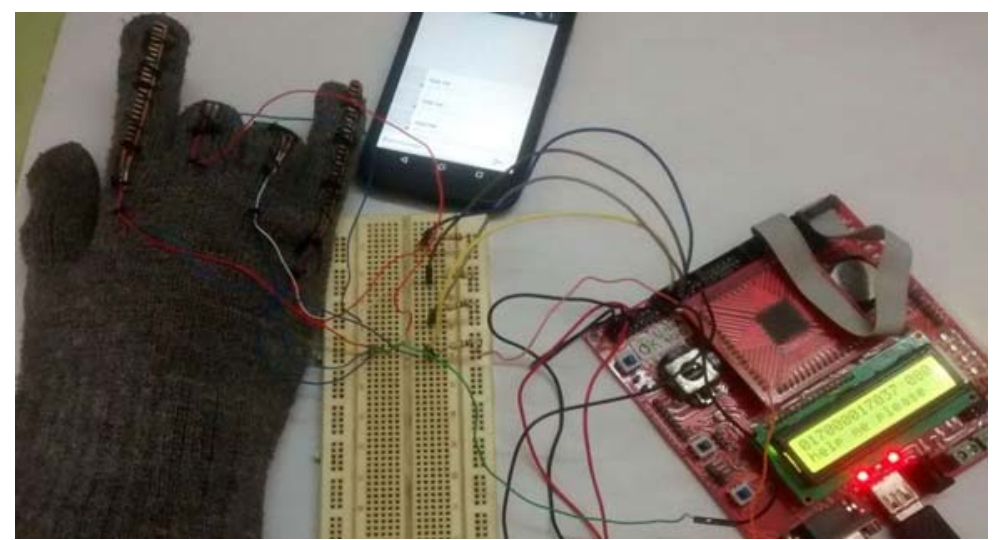

Fig 8 showing message (HELP ME PLEASE )

\section{CONCLUSION}

Hand Gesture Recognition System is very useful Microcontroller Device for Dumb and Paraplegics, Disabled too. The system displays a message on LCD screen upon recognition of user gesture and it also sends message to concerned mobile phone through a GSM module in case of Emergency. Light and fan can also be controlled with the usage of Accelerometer by tilting it. The system is portable and can be carried out to any place without any difficulty and also very easy to wear as the system can be mounted on a glove.

\section{FUTURE SCOPE}

The above system can be extended to make dumb people to communicate with the blind people by introducing a voice synthesizer. More Number of Gestures can be added to the database to communicate more effectively. The robot control system to regulate machine activity at remote sensitive sites.

The communication system can act as an useful device for old persons and the helpless .Furthermore, it would help as a temporary device for the patients who are unable to communicate in hospitals and also Heart Beat Monitoring system can also be collaborated by which doctor can continuously monitor patient heart condition with an automated message.

\section{ACKNOWLEDGMENT}

We thank to the Department of Electronics and Communication Engineering, MVGR College of Engineering (A), vizianagaram for constant motivation and support through-out the work.

\section{REFERENCES}

[1] Praveen Gurav, Ashwini Hunshyal, Akshata Lagamannavar,Akshata Somangoudar, Ambika Talawar, "Gesture Vocalizer for dumb people” International Journal of Current Trends in Engineering \& Research (IJCTER),e-ISSN 2455-1392 Volume 2 Issue 5, May 2016.

[2] Sachin Bhat, Amruthesh M, Ashik, Chidanand Das, Sujith, “Translating Sign Language into text using flex sensors”,International Journal of Advanced Research in Computer and Communication Technology, Vol. 4, Issue 5, May 2015, ISSN (Print) $2319-5940$.

[3] Bhavina Patel, Vandana Shah, Ravindra Kshirsagar, "Microcontroller based gesture recognition system for the handicap people", Journal of Engineering Research and Studies, E-ISSN 0976-7916.

[4] Bhamare Mamata, Malshikare Tejashree, Salunke Renuka and Waghmare Priyanka. (2012). GSM Based LAN Monitoring and Controlling. International Journal of Modern Engineering Research (IJMER), ISSN: 2249-6645, Vol.2, Issue. 2, 387-389. 